\title{
Lecturers' Role in Tutor Development from an Activity Theory Perspective
}

\section{Salochana Lorraine Hassan}

Cape Peninsula University of Technology Email: hassanl@cput.ac.za

\section{Doi:10.5901/mjss.2014.v5n15p391}

\begin{abstract}
Social interactions in tutoring, particularly from the perspective of tutor-lecturer interactions, remain largely unexplored. From an activity theory angle, this study draws on the notion of knotworking to describe the post-training support that lecturers give to tutors in an attempt to help them cross the tutoring Zone of Proximal Development (ZPD). A qualitative paradigm was adopted in this study and involved face-to-face interviews with lecturers and tutors. The theoretical framework used was activity theory. The findings showed that rather than being a structured, formal process, post-training occurred in a loose, flexible, unstructured and informal manner. Knots were tied, untied and sometimes retied as the tutoring community worked together to achieve the object, which was the development of tutors. Hence, knotworking was used as a tool in achieving the object. This article also identified the constraints that impeded knotworking, such as the power struggle that existed between lecturers and tutors and how some lecturers refused to work with and help tutors cross the tutoring ZPD. One of the recommendations advanced is that lecturers themselves need training on how to conduct tutorials and how to mentor tutors in order to create an alignment between student development (training of tutors) and staff development (training of lecturers). Other recommendations for improving post-training support for tutors focus on addressing the constraints inherent in the activity system of post-training support.
\end{abstract}

Keywords: activity theory; knotworking; tutoring; tutor training; zone of proximal development;

\section{Introduction}

Most of the tutoring literature alludes to tutors' experiences of tutorials and the positive effects on tutors (see Retna, Chong \& Cavana, 2009; Schleyer, Langdon \& James, 2005). The exploration of social interactions in tutoring occurs with less frequency and when it does occur the focus is mostly on tutor-student interactions (Colvin, 2007; Colvin, Fozdar \& Volet, 2012). For example, the Colvin (2007) study addresses social dynamics involved in tutoring and the misunderstandings and power struggle that exists between tutors and students. Tutors have to continually manage the way they are perceived by others and have to constantly establish their credibility and value to students. Colvin et al. (2012) also focus on inter-cultural interactions between tutors and students, in tutorial settings.

The relationship between tutors and lecturers is under-represented in the tutoring literature. The study described in this article attempted to correct that deficiency by documenting the interaction between tutors and lecturers and by explaining how that relationship influenced the journey of the tutor along the Zone of Proximal Development (ZPD). This study highlighted the important role that lecturers played in developing tutors and the necessity for staff development initiatives that would focus on training and developing lecturers to work collaboratively with tutors so that their role in conducting tutorials could be more meaningful.

Other gaps in the literature are: 1) discipline-specific training for tutors and 2) the role of lecturers in providing support for tutors. The voice of the lecturer has been neglected with most studies (see Ching \& Chang-Chen, 2011; Comfort, 2011; Topping, 1998) focusing on the role and perceptions of tutors and students. This study addresses these gaps by focusing on the role that lecturers played in providing support to tutors so that they could execute their tasks more effectively as facilitators of learning within tutorials.

In the study reported in this article, the Tutor Training Programme (TTP) was dichotomized into a centralized and decentralized model. Generic training was offered by one of the faculties, through a de-centralized model and by the Academic Development Centre, through a centralized model. Discipline-specific training was not being provided, the expectation being that tutors would subsequently receive post-training, discipline-specific support in their respective departments-this has been reported elsewhere (Hassan, 2013).

The impetus for this study was the lack of information regarding the nature of de-centralized, discipline-specific training within departments and whether this was indeed taking place. The purpose of this study, therefore, was to 
determine how tutors were being supported and mentored within their departments in order to enhance their knowledge and skills in terms of facilitating learning within tutorials.

The study was guided by two research questions: 1) How are tutors trained and developed at departmental level for their role as facilitators of learning within tutorials? 2) What is the nature of support that lecturers provide to tutors to help them cross the ZPD and what is constraining that journey?

In order to address the research problem and answer the research questions, the perspective of both lecturers and tutors regarding tutor training and support were addressed against the background of activity theory. Activity theory was used as a theoretical frame of reference in the design of the study as well as in the collection and analysis of data.

\section{Theoretical Framework}

Activity theory has been used to some extent in other studies pertaining to tutoring. For example, Joyes (2008) explores the use of online tools in the professional development of online tutors. The application of activity theory in the evaluation of tutor training is quite uncommon. This study addresses that void.

The attractiveness of employing activity theory is that the relationship between its elements can be identified and better understood, especially in terms of identifying constraints (Blackler, 1993; Engeström, 1987). Activity theory, therefore, is well suited to an evaluation study, which would examine the very elements that are contained in activity theory and the pinpointing of constraints would augur well for making judgments on quality.

This study addresses three constructs central to activity theory, namely: activity system, contradiction and the ZPD (Engeström, 2008). Further, given the collaborative nature of planning and implementing tutorials, it was deemed important to include a further construct, namely knotworking.

\subsection{Activity system}

Activity theory addresses the following: 1) What the activity is (object); 2) The person or group that is engaged in the activity (subject); 3) What people do (division of labour or roles); 4) What resources they use (tools); 5) What rules (for example, policies) are in place to govern the activity and 6) Who is involved in the activity (community).

In addition, Blackler (1993:871) points out that: 'activity systems do not exist in isolation one from another, the output of one system provides the inputs to another'. In this study, the output of the generic training (see Hassan, 2013) was the production of potential tutors for implementation of tutorials in departments. Subsequently, these tutors needed discipline-specific training from lecturers, creating another activity system which is depicted in figure 1 , which is the focus of this study.

This activity system (see figure 1) comprised an interaction between the subject (lecturers ), tools (knowledge and skills, course materials), object (support for tutors), outcome (enhancement of learning), rules (manner in which tutors are allowed to work with lecturers), community, which refers to individuals who share a common object (tutors, lecturers and link lecturers) and division of labour, which pertains to the horizontal tasks assigned to each member and the vertical division of power and status (Engeström, 2001), (role of lecturers, link lecturers and tutors).

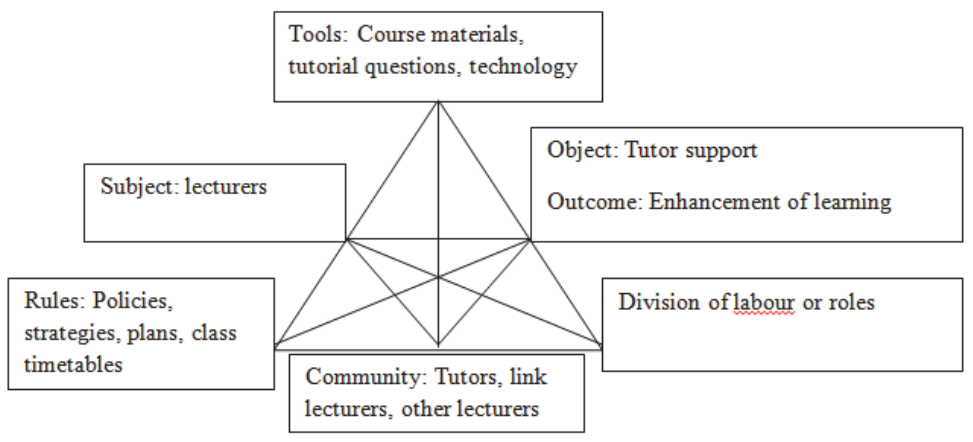

Figure 1. Activity system showing the interacting elements of the post-training, discipline-specific support for tutors in departments 


\subsection{Contradiction}

Engeström's (2008) view of contradiction is that it is the key to understanding the source of the problem in addition to having a developmental potential: 'contradictions manifest themselves in disturbances and innovative solutions. In this sense, an activity system is a virtual disturbance and innovation-producing machine' (Engeström, 2008, p. 205).

Engeström (1987) and Roth (2004) state that contradictions can be found at different levels within and between activity systems. Contradictions that occur within elements are referred to as primary level contradictions. Contradictions that manifest between elements are termed secondary level contradictions. Between activity systems, contradictions occur at the tertiary and quaternary level.

Blackler (1993, p. 871) warns that contradictions within activity systems can become an inherent 'taken-for-granted feature of life'. People will subsequently develop strategies to work around systemic tensions which then become less apparent and invisible. Activity theory functions to make these tensions explicit, to bring them to the foreground and to provide the nomenclature and conceptual framework for describing their position in the activity system (Hopwood and Stocks 2008).

\subsection{Zone of Proximal Development}

The ZPD, which was developed by Vygotsky (1978, p. 86), offered the hypothesis that we can understand the potential for human development if we compare what a person can achieve on their own, without support and what they can accomplish with the assistance of a more experienced, more learned person. Engeström (1987) adopts the concept of ZPD in an expanded sense that transcends the development of the individual, to 'characterize the developmental potential of collective activity systems interacting with other activity systems, both supportive and adversial' Engeström (1987, p. 174).

By linking ZPD and contradiction, this article explores the factors that restricted and disturbed the tutors' journey through the ZPD. In doing so, the second research question for this study was addressed.

Engeström (1987) suggests that the incoherencies and dilemmas within an activity system mark out its ZPD and provide the rationale for and capacity for collective learning. Hopwood and Stocks (2008) indicate that activity theory serves as a toolkit for analyzing the complex interactions between different groups of people and their social environment. They also suggest that the notion of an activity system acts as a tool to connect individual experiences with wider systemic elements and tensions (Hopwood and Stocks, 2008).

\subsection{Knotworking}

Knotworking is a general perspective on emerging new forms of collaborative work and the fluid forms that characterize knotworking are becoming increasingly relevant as forms of organizing work (Engeström, 2008). Engeström (2008. P. 194) maintains that:

'The notion of knot refers to rapidly pulsating, distributed, and partially improvised orchestration of collaborative performance between otherwise loosely connected actors and activity systems. Knotworking is characterized by a movement of tying, untying and retying together seemingly separate threads of activity.'

When knotworking exists people 'solve complex problems and contribute to the reshaping of the entire way of working in their given fields. Their efficacy and value lie in their distributed agency, their collective intentionality' (Engeström, 2008, p. 225). Describing the nature of distributed agency and collective intentionality, Engeström (2008, p. 216) writes that:

'There is no fixed and stable centre of control or command yet the job gets done by means of several seemingly separate or weakly connected strings of actions that take place over an extended period of time and far apart from one another in geographical space'.

In this paper knotworking is explored in terms of how lecturers, link lecturers and tutors work together as a community given that there is no central, hierarchical system or co-ordination of the tutoring system at the University. Each department and each faculty has its own unique modus operandi. While the generic training of tutors is highly coordinated (see Hassan, 2013), the post-training support when they get back to their departments is not. Linking the ZPD and knotworking, the article explores how lecturers collaborate with tutors to provide an enabling environment for growth 
and development, in order to expedite the tutors' journey through the ZPD.

\section{Context of the Study and Research Design}

The study was conducted at a University in South Arica and at the time of collecting data, there were approximately 30000 students and 2000 staff members. Most of the (national) students were from educationally and socio-economically disadvantaged backgrounds. The majority of these students spoke English as a second or third language, their first language being Afrikaans, Zulu or Xhosa. There were international students as well, predominantly from other parts of Africa, who were mainly French speaking.

The respondents in this study comprised six student tutors and ten lecturers who were selected through purposive sampling. The selection of these respondents allowed for the triangulation of data and for member checks to be done in order to validate the data (see Saldana, 2009). They had to have been involved in the tutorial system and able to relay their experiences of the tutorial system.

A qualitative approach was adopted and involved face-to-face, semi-structured interviews with respondents. Interviews provided a platform for the emergence of the voices that would have become embedded in the activity system (Engeström, 2008; Engeström \& Miettinen, 1999), such as that which is illustrated in figure 1. A further reason for using face-to-face interviews was that the mapping of contradictions required careful attention to detail and necessitated the application of appropriate research methods such as interviews (see Blackler, 1993).

Of the six tutors who were interviewed, two had been trained through the de-centralized model and four were trained through the centralized model of the TTP. The duration of the interviews with the tutors ranged between 28-52 minutes. Seven lecturers were interviewed: one had worked with tutors who had been trained through the de-centralized model and six had worked with tutors who had been trained through the centralized model of the TTP. Two of the lecturers in the latter group were link lecturers, that is, they co-ordinated tutorials in their respective departments. The interviews with the lecturers ranged between 30-58 minutes. A digital voice recorder was used during the interviews and handwritten notes were taken. Three lecturers, who were unable to participate in a face-to-face interview but who still wanted to be involved in the study, submitted their typed responses to the interview questions via email.

The data was coded and the codes grouped into various categories. Thereafter, the categories were clustered and themes were identified which were linked to the elements of activity theory. Themes that were not in line with the elements of activity theory were dropped for the purposes of keeping the data uncomplicated (see Saldana, 2009). Only themes that helped answer the research questions cited previously in this article were selected.

\section{Results}

\subsection{Feedback on generic tutor training as an output of a previous activity system}

Tutors had attended a two-day generic TTP which constituted an activity system in itself (see Hassan, 2013). In general, positive comments were made by the lecturers, for example: 'tutors enjoy the [Academic Development Centre] training'. The TTP helped tutors develop personally and professionally and many reported an improvement of their academic performance. Some of the responses from tutors are given as follows:

Tutor 1: 'A good programme- [it] provides a link between the lecturer and the student'.

Tutor 2: 'It's the best .....the best two days at [names the university]'.

Tutor 3: 'In the beginning I failed a lot- I did not know how to study. ... The tutor training programme taught me how to study. I went from fifty percent to seventy five percent. Even [the] lecturers were asking me what happened. After the training I was somebody else.... The [programme] was perfect especially for me. I can dare say its changed my life'.

\subsection{Post-training support for tutors in crossing the Zone of Proximal Development}

The faculty that was providing de-centralized training was meant to be offering discipline-specific training in the field but the training was predominantly generic. The lecturer interviewee within that faculty stated that a short simulation on the conducting of tutorials was done during the TTP but that simply entailed a lecturer presenting a topic in one of the first year subjects. Subjects in other years were not addressed.

Notwithstanding that the perceptions on tutor training were positive, there were mixed responses among tutors regarding post-training support. While some tutors reported receiving support from lecturers, other tutors lamented the lack of involvement of lecturers. After attending the TTP, tutors were excited to apply what they had learnt but in their 
departments they were thrown into the deep end because support for the running of tutorials was not forthcoming. Tutors indicated that when they struggled to interact with students there was nowhere to solicit help.

There was a comment from the tutors that most lecturers had limited knowledge about the processes involved in tutoring and found it difficult to work collaboratively with tutors. There were comments from the tutors that some lecturers even felt threatened by tutors and perceived them to be 'taking over'. One tutor remarked: 'we felt like we were a nuisance'.... I asked myself: do I really feel like I want to do this if I feel I am unwanted?'

Lecturers who worked effectively with tutors adopted a number of strategies to help them cross the tutoring ZPD. They held information briefing sessions with tutors and provided course materials as well as revision questions for the conducting of tutorials. They prepared tutorials and explained to tutors what was expected of them. The lecturer also intervened when tutors were unable to answer questions posed by students during tutorials.

One lecturer explained: 'tutors sometimes forget the content or tell students the wrong thing.' When tutors asked her (the lecturer) questions she told them to 'google it', explicating that tutors needed to be trained on how to search for information in order to improve their discipline knowledge. Some tutors also attended her lectures so that they could 'refresh their memory'.

A few tutors verified that when students approached them for help, they (tutors) sometimes lacked the relevant discipline knowledge. These tutors suggested that the TTP should give tutors an opportunity to revise and consolidate discipline knowledge to enable them to assist students more effectively. The tutors admitted that there was a tendency for them to 'forget' the content.

\subsection{Division of labour between lecturers and tutors within departments}

One lecturer respondent explained that her subject (health sciences) is difficult to learn and that she cannot rely on tutors to explain the concepts (in a formal tutorial setting) because they are only at second year level. What is needed is someone with a lot more experience than that of tutors but there would be little incentive as the 'money is too low'.

In spite of the aforementioned limitations of tutors, there were several positive comments from lecturers regarding the role of tutors:

Lecturer 1: 'We work well as a team, we use the same tutors.'

Lecturer 2: 'There is no professional jealously between tutors and lecturers....we are quite relieved that we have tutors.'

Lecturer 3: "I had the same tutor for three years in a row. She knew exactly what I expected from her. She did well in my subject.... She has more than adequate knowledge.'

Lecturer 4: 'We work well together (with tutors). We have an open door policy.'

Lecturer 5: 'Tutors are alone with students in a tutorial. They need to grow and develop. We have to trust and give them space to grow. We provide a lot of support for our services.'

Lecturer 6: 'We rely on tutors to say if they need more assistance ...We have a close relationship with out tutors, so we feel we can pick up if there is a problem.'

\subsection{Evidence of the impact of enhanced learning among tutors (outcome)}

To a large extent, the role of the tutor was to act as a 'bridge' between lecturers and students because lecturers did not necessarily have the extra time to help their students understand concepts that they were grappling with. There was a remark that some students felt intimidated in class and were afraid to ask questions, in which case the tutors would then explain the (misunderstood) concepts to them. One lecturer proclaimed: "when the lecturer presents, students feel intimidated but when tutors present, they respond better. They (students) openly ask questions and point out areas of difficulty...they respond positively to tutors' knowledge.' Tutors also gave guidance on how to obtain resources and how to use the library. Furthermore, they provided support at a multi-lingual level by explaining concepts in the student's mother tongue language, such as Afrikaans, Zulu, Xhosa or French (see Hassan, 2013).

The lecturers reported that the tutorials were not formally evaluated, however, they were able to provide comments on the impact of tutor support on the quality of students' learning. The following comments were captured and show that tutorials were instrumental in enhancing learning:

Lecturer 1: '[Tutorials] facilitate the understanding of course work.'

Lecturer 2: 'Because of tutorials, they [students] were able to get distinctions.'

Lecturer 3: 'They [students] learnt time management skills and not just academic work.'

Lecturer 4: 'Having a tutor lightens the load; they make a huge difference in my class.'

Lecturer 5: 'One student was struggling and also having problems with language. She spent most of her time in 
[tutorials] and did well.'

Lecturer 6: 'They [students] appreciate tutors and their support. They look forward to class. It is a practice session for them to prepare them for exams.'

\subsection{Logistical matters as contradictions within the rules}

Primary level contradiction was identified within the rules in that despite the acknowledged positive influence of tutorials on students' learning, policies regarding logistical matters such as spatiotemporal and communication issues were being neglected.

There were no dedicated venues for conducting tutorials and this was acknowledged as being problematic. Tutors either used the seminar room in the library or the residences (after hours). One lecturer stated: 'class time is set aside...[tutorials] form part of class time, although it is not indicated in the time table'. As a result, tutors had to make arrangements with students to meet after hours.

It was sometimes difficult for lecturers to contact tutors, especially telephonically, as lecturers were not allowed to use the university telephones to call cellphone numbers. Emails were thus used as an alternative mode of communication, and lecturers depended on chance meetings with tutors in corridors.

\subsection{Contradiction within the role of the subject (lecturers)}

A secondary level contradiction was identified between the subject (lecturer) and the object (support for tutors). Although they were expected to support tutors, they neither received training on how to work with tutors nor how to conduct tutorials; yet all respondents claimed that this was needed. One respondent complained about the lack of communication: 'I feel alone in this process, we used to have monthly meetings and sharing of best practice. None of this happens anymore.'

\section{Discussion}

\subsection{Tension within the tools for tutor training and post-training support}

In this study, although tutors exhibited positive perceptions on the TTP, the generic training they received did not prepare them in terms of discipline specific knowledge and skills which they needed in order to run tutorials effectively. They, therefore, felt that the TTP should have a discipline-specific focus as well. This deficiency in the training of tutors corroborates similar findings in the literature such as the study undertaken by Underhill and McDonald (2010) which showed that the generic tutor training which is offered by the Academic Development Centre neither equipped tutors with discipline-specific skills nor offered a contextual framework. Underhill and McDonald (2010) suggest a modus operandi that involves departments working synergistically with the academic development (AD) practitioner. The AD practitioner is able to obtain more insight into the 'nuances of the discipline that would enable adaptation of the tutor training and development model so that it meets the demands of the discipline.'

\subsection{The notion of knotworking in providing post-training support for tutors to cross the tutoring Zone of Proximal Development}

The nature of the generic TTP that tutors had undergone was structured but within departments, post-training support was unstructured, loose and disconnected. This is a good example of knotworking. Although loose, knotworking had an aim, namely to help tutors cross the ZPD. Knots were created, untied and new knots were formed (see Engeström, 2008) as tutors were supported in their journey across the ZPD.

Lecturers who were members of the tutoring community took leadership at various stages or phases of the tutors' development. The link lecturers, lecturers and tutors worked synergistically and in harmony; there was no hierarchy, no leader who called the shots. Leadership rotated in tandem with the needs of the tutor. Initial training of tutors was undertaken by the Academic Development Centre and one of the faculties, which took leadership in providing generic training. When it came to support in terms of discipline-specific training, the subject lecturer was responsible for mentoring tutors with respect to discipline knowledge especially the content that was to be covered in tutorials. Underhill and McDonald (2010) and Clark (1998) argue that mentorship is an integral component of tutor development and that interacting with the tutor co-ordinator is essential in the mentorship process. Receiving mentoring by the tutor co-ordinator 
places the tutor in a good position, in turn, to mentor students. That is, the tutor would mirror the mentorship they received.

In this study, tutors were mentored by lecturers in terms of discipline knowledge (discipline-specific training) by being given course materials, being allowed to attend lectures and by having debriefing meetings. This constituted one type of knot. Thereafter, the knot was untied when tutors worked on their own in facilitating tutorials. The knot was retied when they returned to work with the lecturer by attending lectures to refresh their memory in terms of the discipline knowledge. Another knot was tied when the lecturer and tutor kept in contact via email communication. (Beaumont, Stirling \& Percy (2009) report that despite the advances in technology, email is the major form of communication between tutors and lecturers).

A knot was also created when tutors helped students, giving tutors an opportunity to apply their knowledge and skills. Here, knotworking was strengthened by the appropriate use of language when tutors explained concepts in the students' mother tongue language. (The importance of tutors in facilitating the learning of students not studying in their mother tongue has been acknowledged by other researchers (Underhill \& McDonald, 2010)).

Ultimately, when tutors needed help with administrative matters such as claiming for numeration of services rendered, they would create a knot with the link lecturer who would co-ordinate the process. Some tutors experienced bureaucratic problems with claiming for remuneration which depicts primary level contradiction within the element pertaining to rules governing financial matters.

The study also found that knotworking was not a power-free space. Power dynamics existed when lecturers were supposed to be involved in developing and supporting tutors. Some lecturers were reluctant to utilize tutors and perceived them as being ill-prepared in terms of the discipline-knowledge. These lecturers did not 'trust' tutors and there was little opportunity for them to conduct tutorials except after hours in the student residences. Other lecturers were unwilling to provide guidance and assistance to tutors which became evident when they did not share resources with tutors.

\subsection{The need for a Zone of Proximal Development for the subject (lecturers)}

The importance for lecturers to be trained on how to work with tutors and how to plan tutorials needs to be recognized. This argument overlaps with Colvin's (2007, p. 178) assertion that:

'....it is apparent that the use of peer tutors is not something that can be grafted onto a standard classroom configuration with automatic success-the system must be designed specifically with peer tutors in mind. It is a whole system of training and support concerning the socialization of students, teachers and instructors in the interaction.'

A contradiction was identified in that tutors were selected and sent for generic training so that they would be able to conduct tutorials but once they had completed their training, they were not trusted by the lecturer (in the health sciences faculty) to run tutorials within a structured setting. That is, the knowledge of the tutor was not perceived to be adequate. This depicts tension between division of labour and the community.

Since tutors were not trusted to support students' learning, other individuals, such as more senior students, would have had to be included in the tutoring community. This was not possible though because the renumeration for tutors was too low. Thus, the rules (amount that tutors were paid) were constraining the membership of the community, giving rise to a tension between rules and community.

The division of labour implied that some lecturers were unwilling to give tutors the opportunity to conduct tutorials and to develop their facilitation skills. Therefore, there was tension between the division of labour, object and envisaged outcome. There was also tension between mediating tools and the object when tutors were not given the resources (for example, notes, handouts, support of lecturers) to enable them to facilitate tutorials effectively.

What was constraining lecturers in helping tutors cross the ZPD? From the data obtained the following variables were identified: 1 ) the attitude of lecturers towards tutors, that is, a lack of trust that they would be able to help students effectively; 2) the perception of tutors as a burden or nuisance and 3) the absence of training for lecturers on how to conduct tutorials and how to mentor tutors. Thus, there was under preparedness among lecturers for supporting tutors and concomitant with time constraints, some tutors were being marginalized. 


\section{Conclusion}

In this study, Engestrom's notion of knotworking (borrowed from activity theory) was applied in explaining the nature of post-training and development of tutors in their journey across the tutoring ZPD.

The recommendations made for improvement of the tutorial system address how tensions can be relieved or alleviated. For example, the tension between the division of labour and rules where lecturers tend to be territorial should be relieved so that tutors are allowed to run tutorials, which should feature on class time tables.

In order to relieve this tension, the rules need to change with a ruling that it be mandatory for tutors to conduct tutorials. In terms of relieving the tension between community and object, opportunities for tutors to interact with other tutors should be created.

Further, there was tension between rules and community in that the rule regarding renumeration for tutors was constraining membership of the community because the rules on tutor salary was preventing people with higher qualifications and more experience from being employed as tutors, at a higher salary.

A training programme for lecturers on how to conduct tutorials and how to mentor tutors should be in place. Reverting to figure 1, this study showed that the lecturer is not simply the subject but a mediating tool in addressing the object of training tutors. Taking this to another level and as part of an activity system for future studies, Engeström (2008) notes how the tool can become the object. In this study, if we regard lecturers as being mentors to tutors, that is, as part of the mediating tool, then the tool should become the object in future studies. That is, the focus should be on how lecturers should be supported and lecturer development should become the object. The tension between tool and object (tutors not getting support from lecturers) can then be addressed through lecturers being trained as mentors to tutors. Ultimately, lecturers would have their own ZPD in terms of learning how to mentor tutors.

A limitation of this study was that a small sample was used. However, the data acquired was rich and when analyzed against the framework of activity theory, proved adequate in identifying gaps and inconsistencies in the development of tutors.

A further limitation might have been the use of activity theory as a framework; its deficiencies being well noted by other researchers. Critiquing activity theory, Blackler (1993) points out that although it focuses on incoherencies as an aspect of social and personal life, it is restrictive when it comes to explaining phenomena. In addition, the view that inconsistency provides the impetus for individual and collective learning is neither accompanied by an explanation of what such learning is nor how it occurs. Blackler's (1993) criticism of activity theory, however, focuses more on what the theory does not cover rather than focusing on why the theory does not work. For Hopwood and Stocks (2008), activity theory is not fully developed in respect of issues such as identity, agency and power. These issues were not the focus of this study and their omission did not compromise the findings.

The take home message in this article is that there was no need for a structured, rigid, hierarchical co-ordination of post-training, discipline-specific support for tutors because knotworking, as a loose, unstructured tool, was functioning well in achieving the outcome of tutor development, in the various departments.

\section{References}

Beaumont, R., Stirling, J., \& Percy, A. (2009). Tutors' forum: Engaging distributed community of practice. Open learning: the Journal of Open Distance and e-learning, 24(2), 141-154.

Blackler, F. (1993). Knowledge and the theory of organizations: Organizations as activity systems and the reframing of management. Journal of Management Studies, 30(6), 863-884.

Ching, C., \& Chang-Chen L. (2011). A case study of peer tutoring program in higher education. Research in Higher Education Journal, 11, 1-10.

Clark, S. (1998). Tutor development: Finding a language for teaching. In S. Angelil-Carter (Ed.), Access to success: Literacy in academic contexts (120-133). Cape Town: University of Cape Town Press.

Colvin, J.W. (2007). Peer tutoring and social dynamics in higher education. Mentoring and Tutoring, 15(2), 165-181.

Colvin, C., Fozdar, F. \& Volet, S. (2012). Intercultural interactions in university tutorials: A Bourdieusian analysis. In N. Brown, S.M. Jones S.M. \& A. Adam (Eds.), Research and Development in Higher Education: Connections in Higher Education, Vol 35 (11-22) . Hobart: Australia.

Comfort, P. (2011). The effect of peer tutoring on academic achievement during practical assessments in applied sports science students. Innovations in Education and Teaching International, 48 (2), 207-211.

Hopwood, N., \& Stocks, C. (2008). Teaching development for doctoral students: What can we learn from activity theory? International Journal for Academic Development, 13(3), 187-198.

Engeström, Y. (1987). Learning by expanding: An activity theoretical approach to developmental research. Helsinki:OrientaKonsultit Oy. 
Engeström, Y. (2001). Expansive learning at work: Toward an activity theoretical re-conceptualization. Journal of Education and Work, 14(1), 133-156.

Engeström, Y. (2008). From teams to knots: activity theoretical studies of collaboration and learning at work. Cambridge: Cambridge University Press.

Engeström, Y., \& Miettinen, P. (1999). Perspectives on activity theory. Cambridge: Cambridge University Press.

Hassan, S. (2013). Evaluation of a tutor training programme through the frame of activity theory. In S. Frielick, N. Buissink-Smith, P., Wyse, J., Billot, J. Hallas \& E.Whitehead (Eds.). Research and Development in Higher Education: Vol 36. The Place of Learning and Teaching (pp. 200-212). Auckland: Higher Education Research and Development Society of Australasia, Inc.

Joyes, G. (2008). An activity theory approach to researching tutors' perceptions of effective online pedagogy. Educational Media International, 45(3), 231-243.

Retna, K.S., Chong, E., \& Cavana, R.Y. (2009). Tutors and Tutorials: Students perceptions in a New Zealand University. Journal of Higher Education Policy and Management, 31(3):251-260.

Roth, W. (2004). Activity theory and education: An introduction. Mind, Culture and Activity, 11(1), 1-8.

Saldana, J. (2009). The coding manual for qualitative researchers. London: Sage.

Schleyer, G.K., Langdon, G.S., \& James, S. (2005). Peer tutoring in conceptual design. European Journal of Engineering Education, 30(2), 245-254.

Underhill, J., \& McDonald, J. (2010). Collaborative tutor development: Enabling a transformative paradigm in a South African University. Mentoring and Tutoring: partnership in Learning, 18(2), 91-106.

Topping, K. (1998). The effectiveness of peer tutoring in further and higher education: A typology and review of the literature. In S. Goodlad (Ed.), Students as tutors and mentors. London: Kogan Page.

Vygotsky, L.S. (1978). Mind and society: The development of higher mental processes. Cambridge, MA: Harvard University Press. 